\title{
Neovaginal Cavity Dissection in Gender Affirmation Surgery for Trans Female: Assisted Endoscopic Light Guide Method
}

\author{
Pansritum $\mathrm{K}^{*}$ \\ Kamol Cosmetic Hospital, Thailand
}

*Corresponding author: Kamol Pansritum, MD. Kamol Cosmetic Hospital, 1223 Ladpraow 94, Intraporn Rd., Kwaeng Plabpla, Khet Wangthonglang, Bangkok, Thailand 10310, Email: kamol.p@mtfsurgery.com

\section{Case Report \\ Volume 5 Issue 1}

Received Date: January 01, 2021

Published Date: February 01, 2021

DOI: $10.23880 /$ ijtps-16000153

\section{Abstract}

Background: One of the most challenging and critical procedures for gender affirmation surgery in trans female is neovaginal cavity dissection due to its variation in the pelvic cavity.

Patients and methods: To describe the method of neovaginal dissection in male-to-female gender confirmation surgery using an assisted light guide method, and surgical landmarks.

Results: A total of 116 patients aged 19-72 years (mean, 28.9) underwent neovaginoplasty using this technique between January 2018 and December 2019. Patients without a light guide method were excluded from the study. Intraoperative rectal injury and postoperative rectovaginal fistula were not found after one year of follow-up.

Conclusions: The use of an assisted light guide method minimizes the rate of rectal injury. The plane of dissection anterior to the prostaticovesicular fascia is the key to success.

Keywords: Perineal dissection; Gender confirmation surgery; Sex reassignment surgery; Gender Affirmation surgery; Gender reassignment surgery; Male-to-Female vaginoplasty

\section{Introduction}

Neovaginal cavity dissection for gender affirmation surgery in trans women is the most challenging step in the overall procedure of neovaginoplasty for female transgender patients. Although the incidence of intraoperative rectal injury and delayed rectovaginal fistula is rare in the literature, the sequelae of these complications are critical and cause patient suffering [1-4].

\section{Study Design}

This study is a case report of perineal dissection in female transgender patients who had undergone genital sex confirmation surgery using an assisted light guide method. The patients were operated by the author at Kamol Cosmetic Hospital. Patients who underwent surgery with other techniques were excluded from the data.

\section{Materials and Methods}

Preoperative management and surgical technique.

The patients must stop hormonal therapy, smoking, aspirin or other anticoagulants, and unimportantmedications 2-4 weeks prior to surgery.

The intestine was cleaned with a double dose of Monobasic sodium phosphate (2.4 g) and Dibasic sodium phosphate $(0.9 \mathrm{mg})$ with normal saline enema.

Preoperative prophylactic antibiotics were administered in all cases. Postoperative antibiotics were administered for 24 hours or more, depending on the individual underlying diseases. 


\section{International Journal of Transplantation \& Plastic Surgery}

The patient was in the anti-Trendelenburg position with the head downward 20-40 degrees, depending on the variation of the pelvis and perineum anatomy. The urinary bladder was catheterized, retained, and filled with 200-300 $\mathrm{mL}$ of normal saline solution to guide its posterior surface.

The perineum incision was an inverted-Y shape with a posterior scrotal flap. Its width is approximately $3.0 \mathrm{~cm}$, and the vertical length is approximately $4.0 \mathrm{~cm}$. Electrocautery was used for the dissection (Figure 1). A low temperature endoscopic intra-rectal-illuminated light guide was used during the dissection (Figure 2). The neovaginal cavity was created anterior to the prostaticovesicular fascia (Denonvilliers' fascia) at the posterior wall of the prostate gland. Then, it was moved upward to the posterior wall of the urinary bladder and beyond the peritoneal reflection that was $10-12 \mathrm{~cm}$ from the perineal skin. Blunt dissection was allowed beyond the peritoneal reflection.

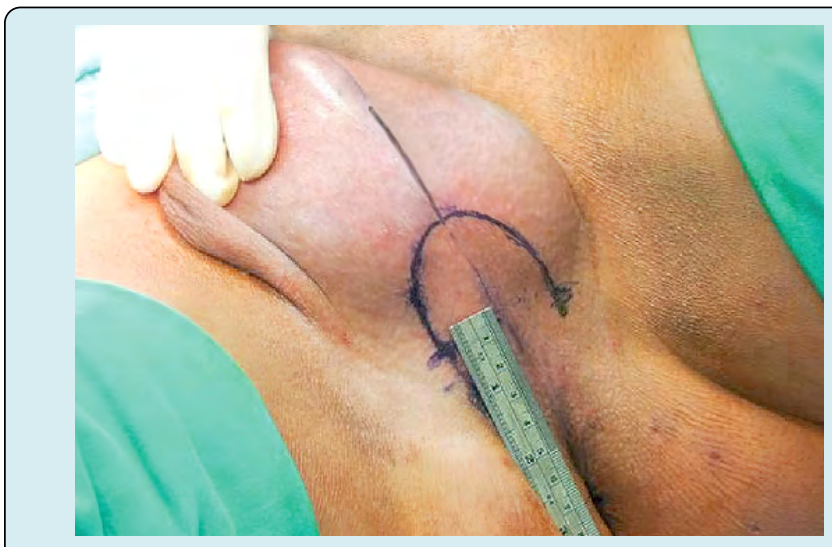

Figure 1: Inverted-Y incision at perineum.

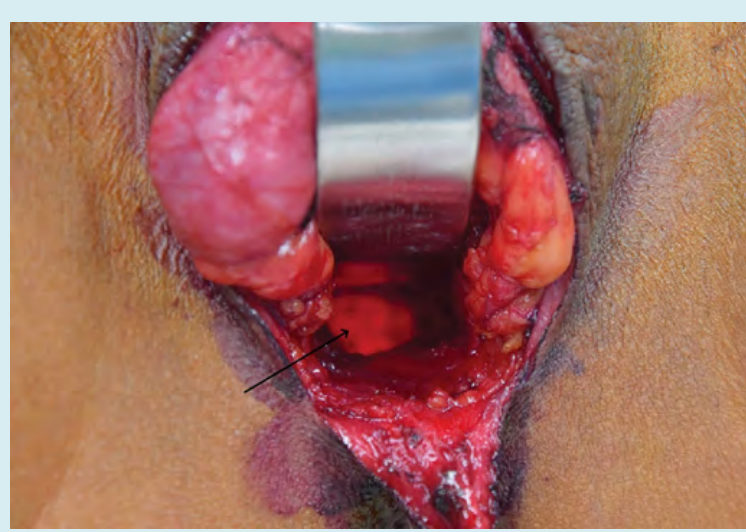

Figure 2: Neovaginal cavity with endoscopic illuminated intra-rectal light guide.

The surgical landmarks of the perineal dissection were divided into three sites (Figures 3, 4, and 5)

1. The first surgical landmark is the Bulbourethral glands (Cowper's glands).
2. The second surgical landmark is the prostaticovesicular junction.

3. The third surgical landmark is the peritoneal reflection at the rectovesicular pouch.

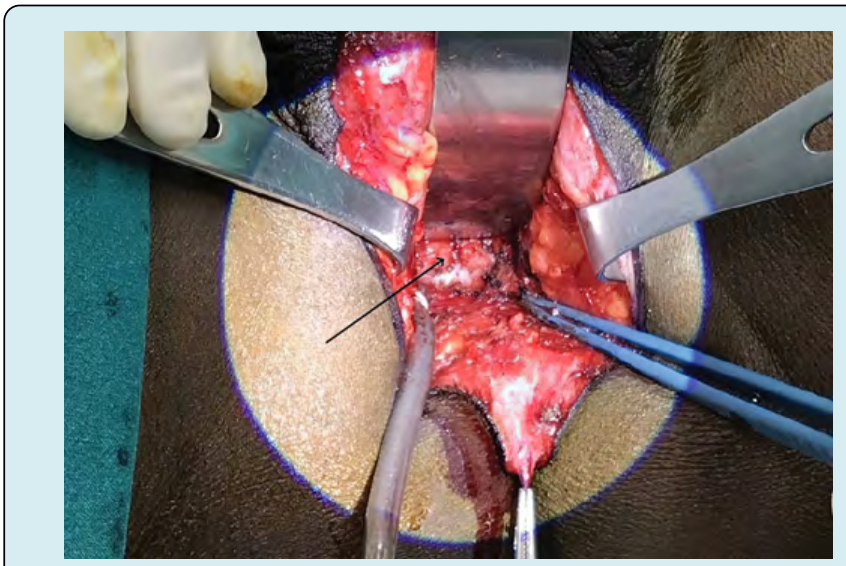

Figure 3: First landmark, Cowper's glands are shown posterolateral to the inferior border of the prostate glands.

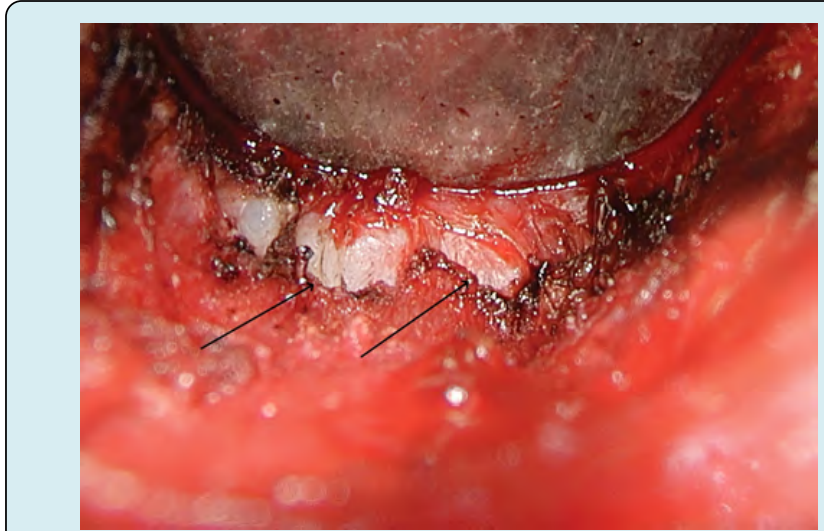

Figure 4: Second landmark, the prostaticovesicular fascia at the inferior border of prostate gland.

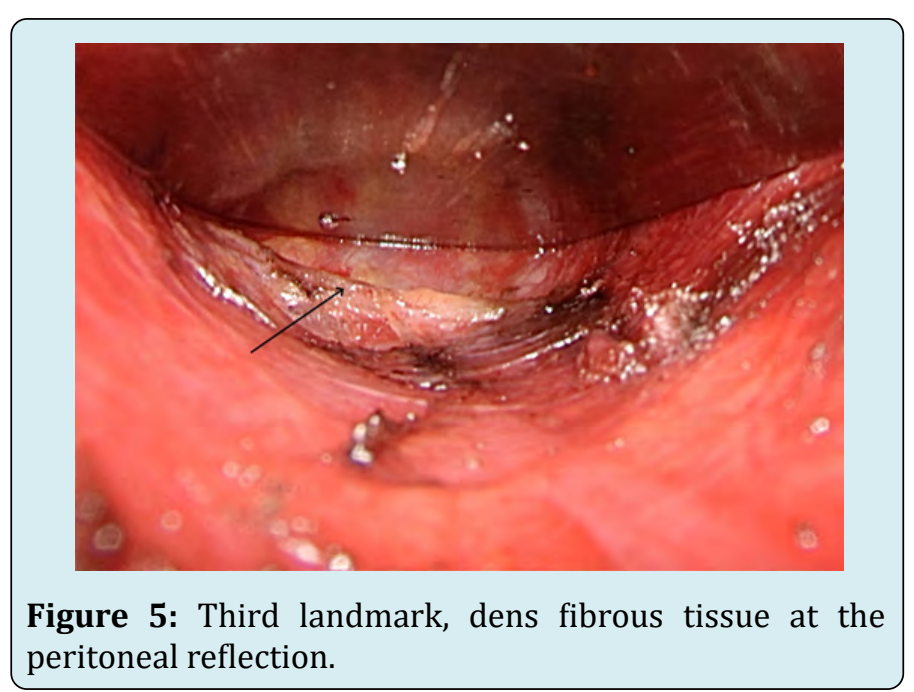




\section{International Journal of Transplantation \& Plastic Surgery}

\section{Results}

Between January 2018 and December 2019, 116 patients aged 19-72 years (mean, 28.9 years) underwent male-to-female gender confirmation vaginoplasty using an assisted light guide method. Penile skin inversion with scrotal skin grafting was performed in 62 patients. The sigmoid colon technique was used in 45 patients, and other techniques were utilized in the remaining nine patients. The duration of the perineal dissection ranged from 16 to $45 \mathrm{~min}$ depending on the type of the neovaginal lining. The depth of the neovaginal cavity ranged from 12 to $15 \mathrm{~cm}$ (mean, 13.4 $\mathrm{cm}$ ). Urine catheters were removed between 6 and 10 days postoperatively.

Minor complications included minor postoperative hemorrhage in four patients and partial skin necrosis in three patients. All cases of neovaginal cavity dissection using this method were successfully performed without intraoperative rectal injury. The intra-neovaginal lining included penile skin with scrotal skin graft and rectosigmoid colon technique. A delayed rectovaginal fistula was not found after 1 year of follow-up.

\section{Discussion}

Several surgeons have described perineal dissection in a personal manner. The authors tended to avoid the blunt technique of perineal dissection as described by some surgeons $[5,6]$. The author believes that the direction of the neovaginal cavity tends to move posteriorly to the muscle layer of the rectum due to the lower density of the soft tissue. It is well known that the prostaticovesicular (Denonvilliers' fascia) fascia is the most reliable landmark for neovaginal dissection; thus, it is used as a landmark by several surgeons, and dissection is done anterior to the fascia. The prostaticovesicular fascia is thickest and most dense at the junction between the prostate gland and urinary bladder and the peritoneal reflection [7].

The author agrees with the technique of dissection anterior to the prostaticovesicular fascia with sharp and blunt dissection as described by several surgeons [8-10]. The space anterior to the prostaticovesicular fascia is the ideal plane for the perineal dissection. Anatomically, the prostaticovesicular fascia is always anterior to the rectal muscle wall. Nevertheless, creation of the space anterior to the fascia is more difficult than the plane posterior to the fascia due to the scarcity of areolar adipose tissue in the latter. A precise and sharp dissection is required. Using the intra-rectal guide as described with iodineembalmed tampon is useful [11]. However, utilization of the endoscopic illuminated low-temperature light guide would be more beneficial and less likely to cause surgical wound contamination. In this way, adequate visualization of the cavity may be done. Special consideration must be taken regarding the density of the light because when the density of the illuminated light is too high, the posterior wall of the cavity may be too thin and too close to the rectal mucosa. The surgeon may then change the direction anteriorly or finish the dissection process. Intermittent and short duration of using a low-temperature intra-rectal illumination is recommended to avoid rectal mucosa thermal injury. Moreover, the surgeon performs the endoscopic rectal examination simultaneously as well. Approaching the lateral sides before dissection of the tendinous center and then cutting the rectourethral muscle to access the deep part of the cavity as described by Perovic [8] would avoid the possibility of rectal injury, but would increase the chance of hemorrhage due to higher vascularity at the lateral areas. The author agrees with Wangjiraniran $B$, according Preecha technique, used normal saline-filled urinary bladder to make the posterior wall convex, which would allow clearer visualization of the wall of the urinary bladder [12]. The robotic-assisted approach used by Rude $\mathrm{T}$, et al. would be helpful, however, limitations include the cost and availability of the instruments required for this procedure [13].

\section{Conclusion}

Neovaginal cavity dissection is one of the most challenging procedures for gender affirmation surgery in trans female. Defining surgical landmarks is important for reducing the risk of excessive hemorrhage and rectal injury. The use of the endoscopic low-temperature intra-rectum light guide is beneficial in reducing the rate of rectal injury.

Patient Consent: The patients provided written consent for the use of their images.

Conflicts of Interest: The author has nothing to disclose.

Declaration of Interest: Financial Disclosure: Dr. Kamol Pansritum has nothing to disclose. No funding was received for this article.

\section{References}

1. Lawrence AA (2006) Patient-reported complications and functional outcomes of male-to-female sex reassignment surgery. Arch Sex Behav 35(6): 717-727.

2. Raigosa M, Avvedimento S, Yoon TS, Cruz-Gimeno J, Rodriguez G, et al. (2015) Male-to-female Genital Reassignment Surgery: A retrospective review of surgical technique and complications in 60 patients. J Sex Med 12(8): 1837-1845. 


\section{International Journal of Transplantation \& Plastic Surgery}

3. Gaither TW, Awad MA, Osterberg EC, Murphy GP, Romero A, et al. (2018) Postoperative complications following primary penile inversion vaginoplasty among 330 maleto-female transgender patients. J Urol 199(3): 760-765.

4. Rossi Neto R, Hintz F, Krege S, Rubben H, Vom Dorp F (2012) Gender reassignment surgery--a 13 year review of surgical outcomes. Int Braz J Urol 38(1): 97-107.

5. Bouman MB, van Zeijl MC, Buncamper ME, Meijerink WJ, van Bodegraven AA, et al. (2014) Intestinal vaginoplasty revisited: a review of surgical techniques, complications, and sexual function. J Sex Med 11(7): 1835-1847.

6. Reed HM (2011) Aesthetic and functional male to female genital and perineal surgery: feminizing vaginoplasty. Semin Plast Surg 25(2): 163-174.

7. Muraoka K, Hinata N, Morizane S, Honda M, Sejima T, et al. (2015) Site-dependent and interindividual variations in Denonvilliers' fascia: a histological study using donated elderly male cadavers. BMC Urol 15: 42.

8. Perovic SV, Stanojevic DS, Djordjevic ML (2000) Vaginoplasty in male transsexuals using penile skin and a urethral flap. BJU Int 86(7): 843-850.

9. Stanojevic D, Stanojevic ML, Milosevic A, Sansalone S, Slavkovic Z, et al. (2007) Sacrospinous ligament fixation of neovaginal prolaps prevention in male-to-female surgery. Urology 70(4): 767-771.

10. Rehman J, Melman A (1999) Formation of neoclitoris from glans penis by reduction glansplasty with preservation of neurovascular bundle in male-to-female gender surgery: functional and cosmetic outcome. J Urol 161(1): 200-206.

11. Rossi Neto R, Hintz F, Krege S, Rübben H, vom Dorp F (2012) Gender reassignment surgery - a 13 year review of surgical outcomes. Int Braz j Urol 38(1): 97-107.

12. Wangjiraniran B, Selvaggi G, Chokrungvaranont $P$, Jindarak S, Khobunsongserm S, et al. (2015) Male-tofemale vaginoplasty: Preecha's technique. J Plast Surg Hand Surg 49: 153-159.

13. Rude T, Khurana K, Weinberg A, Levine J, Stifelman M, et al. (2017) V9-06 Robot assisted penile inversion vaginoplasty: a novel technique. J Urol 4: e1058. 